\title{
KINETICS OF SOLVENT EXTRACTION OF COPPER(II) WITH 2-ETHYLHEXANAL OXIME
}

\author{
KATSUTOSHI INOUE, YOSHINARI BABA AND YOSHIHIRO NAKASHIMA \\ Department of Applied Chemistry, Saga University, Saga 840
}

Key Words: Extraction, Extraction Kinetics, Copper(II), 2-Ethylhexanal Oxime, Non Chelating Oxime, Chloride Media

\begin{abstract}
The kinetics of solvent extraction of copper(II) from aqueous sodium chloride solution with 2-ethylhexanal oxime in toluene was investigated, along with the aqueous distribution and the interfacial adsorption equilibrium of the extractant. 2-Ethylhexanal oxime was found to have rather high aqueous solubility and interfacial activity. The extraction rate was found to have a first-order dependence with respect to the concentration of neutral copper(II)-dichloro complex, $\mathrm{CuCl}_{2}$, and a second-order dependence with respect to that of the extractant. From these concentration dependencies of the reactant species, the extraction rate was inferred to be controlled by desorption of the final 1:2 metal: reagent complex from the interface brought about by substitution with the extractant molecule.
\end{abstract}

\section{Introduction}

Oxime compounds as metal extractants are divided into two groups: chelating and non-chelating oximes. Among chelating oximes, commercial hydroxyoximes such as LIX $63,64 \mathrm{~N}, 65 \mathrm{~N}, 860,622$ and Acorga's P5000 series reagents have found large-scale commercial application, especially in copper hydrometallurgy. Chelating oximes other than hydroxyoximes, such as $\alpha$-dioximes ${ }^{3)}$ and $\alpha$-aminooximes, ${ }^{13)}$ are also interesting metal extractants from the viewpoint of commercial applications in hydrometallurgy. ${ }^{12}$ Consequently, numerous works have been done on the chelating oximes in terms not only of their fundamental aspects in solvent extraction but also of their practical applications.

By contrast, only a small number of works have been done on the non-chelating oximes. They are classified into two groups; aldoximes and ketoximes as shown below.

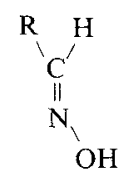

aldoxime

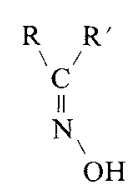

ketoxime
Recently, we found that 2-ethylhexanal oxime, abbreviated to 2-EHO hereafter, is an effective extracting reagent for palladium(II) which can extract from chloride media in much shorter contact time than other reagents such as hydroxyoximes and

Received May 27, 1987. Correspondence concerning this article should be addressed to K. Inoue. sulfur-containing extractants and has an excellent selectivity over platinum (II and IV) and base metals such as copper(II), nickel(II), zinc(II) and so on in the low-concentration region of chloride ion in particular. ${ }^{9)}$ Nevertheless, there has been no investigation of the extraction behavior of 2-EHO as an individual reagent.

In the previous paper ${ }^{109}$ we investigated the equilibrium aspect of the solvent extraction of copper(II) from hydrochloric and hydrobromic acids with 2EHO in toluene to obtain fundamental information on the extraction behavior of this reagent and clarified that it is extracted according to the stoichiometric relation of the solvation reaction mechanism as follows:

$$
\mathrm{CuX}_{2}+2 \overline{\mathrm{B}} \longrightarrow \overline{\mathrm{CuB}_{2} \mathrm{X}_{2}} \quad(\mathrm{X}=\mathrm{Cl} \text { or } \mathrm{Br})
$$

In the present work, we conducted a quantitative investigation of the kinetic aspect of the solvent extraction of copper(II) from aqueous sodium chloride solution with 2-EHO in toluene to elucidate the rate mechanism of the present extraction system.

\section{Experimental}

\subsection{Reagents}

2-EHO was synthesized in the same manner as described in the previous paper ${ }^{10)}$ from 2-ethylhexylaldehyde in ethanol and an aqueous mixture of hydroxylamine hydrochloride and sodium acetate according to the following reaction:

$$
\begin{aligned}
& \mathrm{RCHO}+\mathrm{NH}_{2} \mathrm{OH} \cdot \mathrm{HCl}+\mathrm{CH}_{3} \mathrm{COONa} \\
& \longrightarrow \mathrm{R}-\mathrm{CNOH}-\mathrm{H}+\mathrm{CH}_{3} \mathrm{COOH}+\mathrm{NaCl}+\mathrm{H}_{2} \mathrm{O}
\end{aligned}
$$

After filtration and phase separation, the product 
was purified by vacuum distillation (bp $355 \mathrm{~K}$ / $1.5 \mathrm{mmHg}(1 \mathrm{mmHg}=133.322 \mathrm{~Pa}))$. Identification of the product was carried out by means of IR and NMR spectra. The purity was verified to be about $97 \%$ by gas chromatography. The organic solutions were prepared by diluting this purified product with toluene of analytical grade to a required concentration on a gravimetric basis. The aqueous solutions were prepared by dissolving copper(II) chloride into aqueous sodium chloride solutions of various concentrations.

\subsection{Measurement of aqueous distribution of 2-EHO}

The aqueous distribution of 2-EHO was measured spectrophotometrically at $303 \mathrm{~K}$ by a method similar to that employed for such measurements of sulfurcontaining extractants, 1,2-bis(tert-hexylthio)ethane ${ }^{1)}$ and triisobutylphosphine sulfide, ${ }^{2)}$ in previous works. To an aqueous chloride solution equilibrated with a certain concentration of 2-EHO solution, an excess concentration of aqueous palladium(II) chloride solution and a small volume of toluene were added and shaken vigorously to completely convert 2 -EHO dissolved in the aqueous phase to its palladium(II) complex and extract into the toluene phase. A small amount of the organic phase was taken in order to measure the absorbance of the palladium(II) complex at $283 \mathrm{~nm}$ against a toluene blank using a Shimadzu UV 140 spectrophotometer. The concentration of 2EHO dissolved in the aqueous chloride solution was calculated from the concentration of the palladium(II)-2-EHO complex and the volume ratios of the aqueous to organic phases as well as the stoichiometric ratio in the complexation of palladium(II) with 2 EHO $(=1: 2)$.

\subsection{Measurement of interfacial tension}

The interfacial tension between the toluene solution of $2-\mathrm{EHO}$ and $1 \mathrm{~mol} / \mathrm{dm}^{3}$ aqueous sodium chloride solution was measured at $303 \mathrm{~K}$ by the drop-weight method to elucidate the interfacial adsorption equilibrium of 2-EHO.

\subsection{Measurement of the extraction rate of copper(II)}

The extraction rate was measured using a Lewistype stirred transfer cell of precisely the same geometry and the same size as that used by Yoshizuka et al. ${ }^{14)}$ for measurement of the extraction rate of copper(II) with $n$-8-quinolylsulfonamide.

In a preliminary experiment, it was found that the initial extraction rate is independent of the stirring speed in the range above $150 \mathrm{~min}^{-1}$, suggesting that it is not controlled by the diffusional resistance in either phase in this region. Consequently, stirring of both phases was carried out in opposite directions at a constant speed of $150 \mathrm{~min}^{-1}$ in the subsequent experiments.

A small amount of organic phase was taken at time intervals to measure the time variations of the
copper(II) content in the organic phase. After stripping of copper(II) from the sampled organic phase with $2 \mathrm{~mol} / \mathrm{dm}^{3}$ aqueous ammonia solution, it was determined by means of atomic absorption spectrochemical analysis using a Nippon Jarrell-Ash model AA-782 spectrophotometer.

\section{Experimental Results}

\subsection{Aqueous distribution of 2-EHO}

Figure 1 shows the relation between the concentrations of 2-EHO in the organic phase and in $0.1 \mathrm{~mol} / \mathrm{dm}^{3}$ hydrochloric acid or aqueous sodium chloride solution. The aqueous distribution in the aqueous sodium chloride solution is somewhat greater than that in hydrochloric acid, which is the same tendency as was observed in the measurement of the aqueous distribution of 1,2-bis(tert-hexylthio)ethane in the previous work. ${ }^{1}$

The distribution of 2-EHO between the organic and aqueous phases is expressed as follows:

$$
\overline{\mathrm{B}} \rightleftharpoons \mathrm{B} ; \quad K_{\mathrm{D}}
$$

where $K_{\mathrm{D}}$ denotes the distribution coefficient of 2 EHO and is defined by

$$
K_{\mathrm{D}}=C_{\mathrm{BW}} / C_{\mathrm{B} 0}
$$

The logarithm of Eq. (3) gives

$$
\log C_{\mathrm{BW}}=\log C_{\mathrm{B} 0}+\log K_{\mathrm{D}}
$$

The plots in Fig. 1 lie on straight lines with a slope of 1 for each aqueous chloride medium as expected from Eq. (4). From the intercepts of the straight lines with the ordinate in Fig. 1, the distribution coefficients were evaluated as $K_{\mathrm{D}}=2.2 \times 10^{-3}[-]$ for hydrochloric acid and $K_{\mathrm{D}}=3.4 \times 10^{-3}$ [-] for aque-

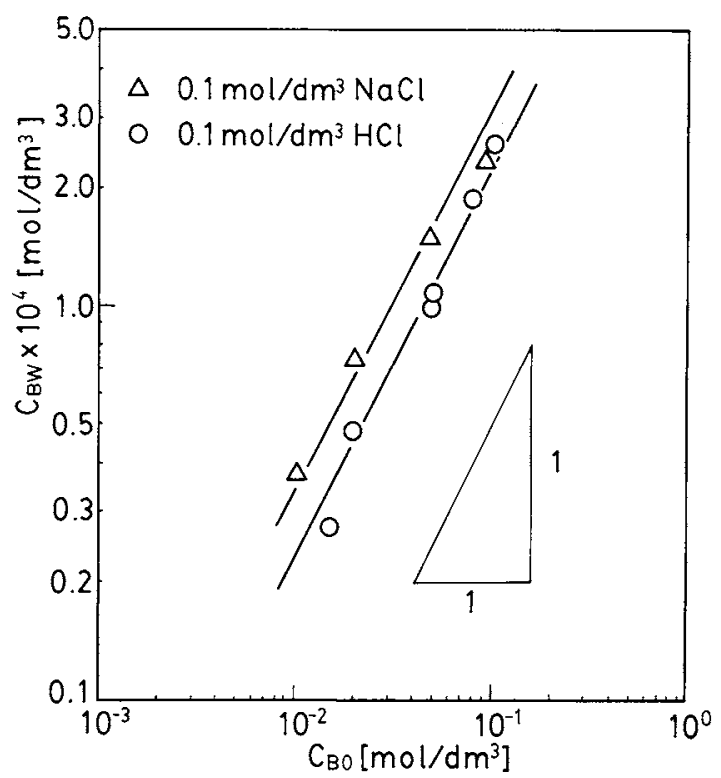

Fig. 1. Aqueous distribution of 2-EHO to aqueous chloride media 


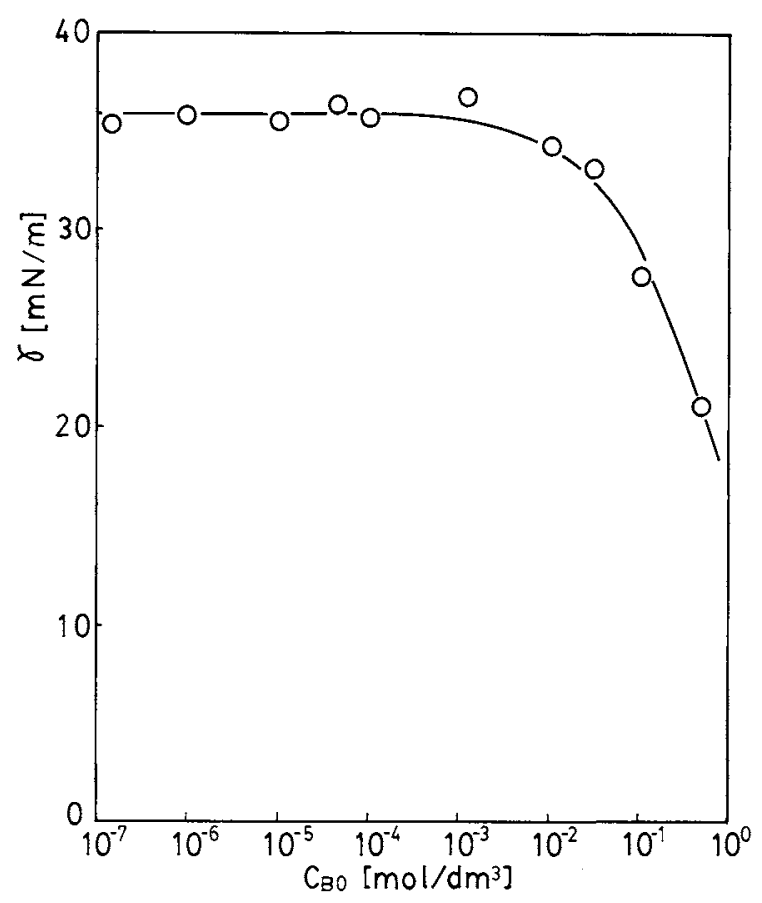

Fig. 2. Interfacial tension between toluene solution of 2EHO and $1.0 \mathrm{~mol} / \mathrm{dm}^{3}$ aqueous sodium chloride solution

ous sodium chloride solution.

\subsection{Interfacial adsorption equilibrium of 2-EHO}

Figure 2 shows a plot of interfacial tension between toluene solution of $2-\mathrm{EHO}$ and $1.0 \mathrm{~mol} / \mathrm{dm}^{3}$ sodium chloride solution against 2-EHO concentration in the organic phase. Decrease in interfacial tension with increasing 2-EHO concentration is observed in its high concentration region, indicating that 2-EHO is interfacially active.

Based on Langmuir's monolayer adsorption model and Gibbs' adsorption isotherm, the relation between interfacial tension and 2-EHO concentration in the organic phase is described as follows: ${ }^{11}$

$$
\gamma=\gamma_{0}-\left(\mathrm{R} T / S_{\mathrm{B}}\right) \ln \left(1+K_{\mathrm{ad}} C_{\mathrm{B} 0}\right)
$$

The interfacial area occupied by unit mole of 2 EHO, $S_{\mathrm{B}}$, and the interfacial adsorption equilibrium constant, $K_{\text {ad }}$, were evaluated by means of the nonlinear least squares method based on Eq. (5) using the data shown in Fig. 2 as follows:

$$
\begin{aligned}
& S_{\mathrm{B}}=4.7 \times 10^{5} \quad\left[\mathrm{~m}^{2} / \mathrm{mol}\right] \\
& K_{\text {ad }}=2.9 \times 10^{-2} \quad\left[\mathrm{~m}^{3} / \mathrm{mol}\right]
\end{aligned}
$$

\subsection{Extraction kinetics}

Initial extraction rates of copper(II) were calculated by the conventional method from the slopes of the linear plots of copper(II) content in the organic phase against the contact time and the interfacial area between two phases as well as the volume of the organic phase according to Eq. (6).

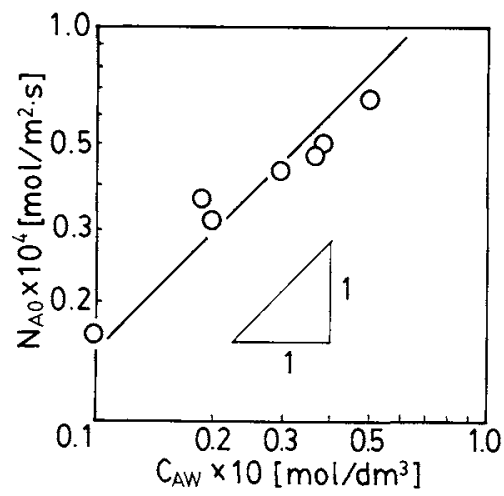

Fig. 3. Effect of copper(II) concentration in aqueous phase on initial extraction rate $\left(C_{\mathrm{B} 0}=0.1 \mathrm{~mol} / \mathrm{dm}^{3},\left[\mathrm{Cl}^{-}\right]=1.5 \mathrm{~mol} /\right.$ $\mathrm{dm}^{3}$ )

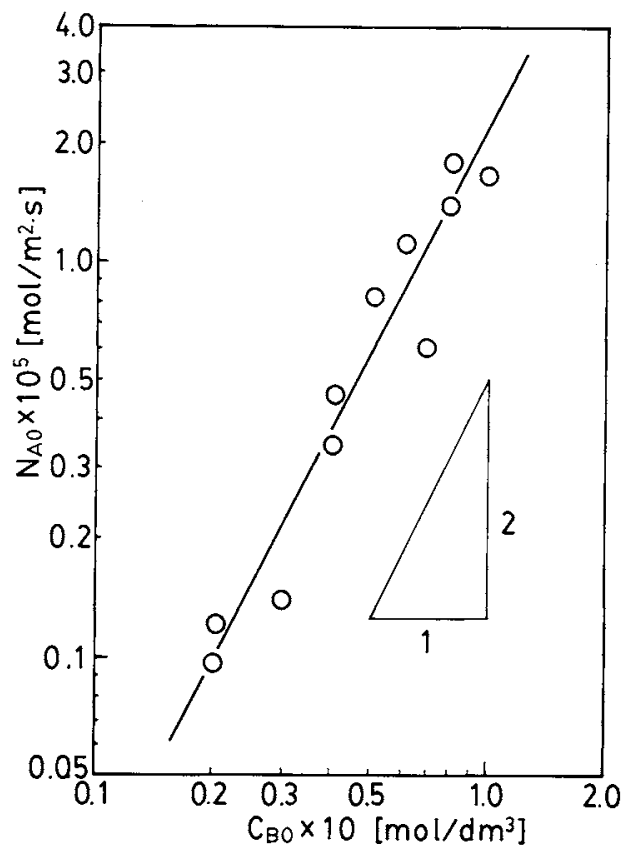

Fig. 4. Effect of extractant concentration on initial extraction rate $\left(C_{\mathrm{AW}}=0.01 \mathrm{~mol} / \mathrm{dm}^{3},\left[\mathrm{Cl}^{-}\right]=1.5 \mathrm{~mol} / \mathrm{dm}^{3}\right)$

$$
N_{\mathrm{A} 0}=\left.\frac{V_{\mathrm{org}}}{S} \cdot \frac{d C_{\mathrm{A} 0}}{d t}\right|_{t=0}
$$

Figure 3 shows the effect of copper(II) concentration in the aqueous phase on the initial extraction rate. The plots lie on a straight line with a slope of 1 , suggesting that the initial extraction rate is first-order with respect to copper(II) in the aqueous phase. Figure 4 shows the effect of the extractant concentration on the initial extraction rate. The plots cluster on a straight line with a slope of 2 , suggesting that the initial extraction rate is second-order with respect to the extractant. Figure 5 shows the effect of chloride ion concentration on the initial extraction rate. The plots lie on a straight line with a slope of 2 in the low-concentration region of chloride ion while they appear to tend to a constant value with increasing chloride ion concentration in the high concen- 


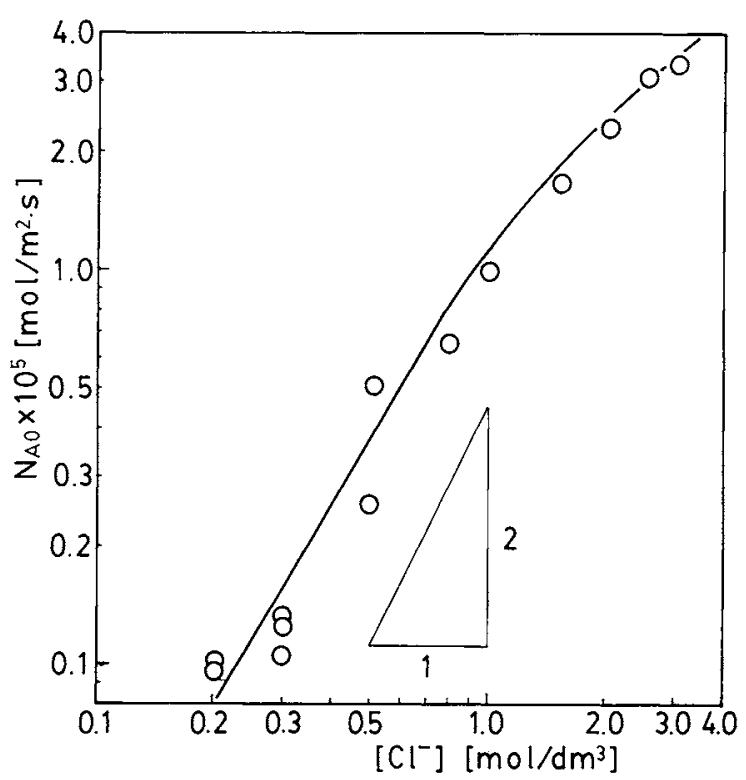

Fig. 5. Effect of chloride ion concentration on initial extraction rate $\left(C_{\mathrm{AW}}=0.01 \mathrm{~mol} / \mathrm{dm}^{3}, C_{\mathrm{B} 0}=0.1 \mathrm{~mol} / \mathrm{dm}^{3}\right)$

tration region.

\section{Discussion of the Extraction Mechanism}

In aqueous chloride media, copper(II) ion undergoes complexations with chloride ion according to the following equilibrium:

$$
\mathrm{Cu}^{2+}+\mathrm{iCl}^{-} \rightleftharpoons \mathrm{CuCl}_{\mathrm{i}}^{(\mathrm{i}-2)-} ; \quad \beta_{\mathrm{i}}
$$

where $\beta_{\mathrm{i}}$ denotes the stability constant of the $i$-th copper(II)-chloro complex. The concentration of the $i$-th copper(II)-chloro complex is expressed by Eq. (8) as a function of total copper(II) concentration in the aqueous phase, $C_{\mathrm{AW}}$, and chloride ion concentration.

$$
\left[\mathrm{CuCl}_{\mathrm{i}}^{(\mathrm{i}-2)-}\right]=\beta_{\mathrm{i}}\left[\mathrm{Cl}^{-}\right]^{\mathrm{i}} C_{\mathrm{Aw}}\left(1+\sum_{j=1}^{4} \beta_{j}\left[\mathrm{Cl}^{-}\right]^{j}\right)
$$

The second-order dependency of chloride ion concentration on the extraction rate in its low concentration region suggests that it is not free aqua ion of copper(II), $\mathrm{Cu}^{2+}$, but the neutral copper(II)dichloro complex, $\mathrm{CuCl}_{2}\left(\mathrm{H}_{2} \mathrm{O}\right)_{2}$, that takes part in the complexation with the extractant molecules, taking account of the fractions of the various chloro complexes of copper(II) in the corresponding concentration region of chloride ion. The neutral copper(II)dichloro complex is considered to undergo consecutive complex formation reactions with the extractant molecules to form the final complex, $\mathrm{CuCl}_{2} \mathrm{~B}_{2}$.

It is possible that the consecutive complex formation occurs in the aqueous phase according to the classical heterophase homogeneous reaction mechanism or at the interface according to the heterogeneous interfacial reaction mechanism.

From the experimental results of aqueous distribution and interfacial adsorption equilibrium, 2-EHO has both high aqueous solubility and high interfacial activity. It might be considered that the high aqueous solubility of the extractant supports the former reaction model while its high interfacial activity supports the latter in interpreting the kinetic data shown in the preceding section.

Based on the former reaction model, the following reaction scheme may be proposed:

$$
\begin{aligned}
\overline{\mathrm{B}} & \rightleftharpoons \mathrm{B} \\
\mathrm{CuCl}_{2}\left(\mathrm{H}_{2} \mathrm{O}\right)_{2}+\mathrm{B} & \rightleftharpoons \mathrm{CuCl}_{2} \mathrm{~B}\left(\mathrm{H}_{2} \mathrm{O}\right)+\mathrm{H}_{2} \mathrm{O} \\
\mathrm{CuCl}_{2} \mathrm{~B}\left(\mathrm{H}_{2} \mathrm{O}\right)+\mathrm{B} & \rightleftharpoons \mathrm{CuCl}_{2} \mathrm{~B}_{2}+\mathrm{H}_{2} \mathrm{O} \\
\mathrm{CuCl}_{2} \mathrm{~B}_{2} & \rightleftharpoons \mathrm{CuCl}_{2} \mathrm{~B}_{2}
\end{aligned}
$$

The observed second-order dependency of extractant concentration on the initial extraction rate suggests that the formation of the final complex in the aqueous phase described by Eq. (11) is ratedetermining. This, however, is apparently contrary to Eigen's authoritative theory ${ }^{7)}$ of complex formation in the aqueous phase.

On the other hand, the following reaction scheme might be inferred as a possible one based on the latter reaction model.

$$
\begin{aligned}
& \overline{\mathrm{B}} \rightleftharpoons \mathrm{B}_{\mathrm{ad}} ; \quad K_{\mathrm{ad}} \\
& \mathrm{CuCl}_{2}\left(\mathrm{H}_{2} \mathrm{O}\right)_{2}+\mathrm{B}_{\mathrm{ad}} \rightleftharpoons \mathrm{CuCl}_{2} \mathrm{~B}\left(\mathrm{H}_{2} \mathrm{O}\right)_{\mathrm{ad}} \\
&+\mathrm{H}_{2} \mathrm{O} ; \quad K_{1} \\
& \mathrm{CuCl}_{2} \mathrm{~B}\left(\mathrm{H}_{2} \mathrm{O}\right)_{\mathrm{ad}}+\mathrm{B}_{\mathrm{ad}} \rightleftharpoons \mathrm{CuCl}_{2} \mathrm{~B}_{2 \mathrm{ad}} \\
&+\mathrm{H}_{2} \mathrm{O} ; \quad K_{2} \\
& \mathrm{CuCl}_{2} \mathrm{~B}_{2 \mathrm{ad}}+\overline{\mathrm{B}} \frac{k_{3}}{k_{-3}} \overline{\mathrm{CuCl}_{2} \mathrm{~B}_{2}}+\mathrm{B}_{\mathrm{ad}}
\end{aligned}
$$

The elementary step described by Eq. (16) represents the desorption of the final complex from the interface brought about by substitution with the extractant molecule; the conception as such was introduced by Danesi $e t a{ }^{4-6)}$ to interpret kinetic data of the extraction of iron(III) with dinonylnaphthalenesulfonic acid or those of hydrochloric acid and iron(III) with trilaurylamine. Provided that the portions of the intermediate and final complexes are negligibly small compared with that of the unreacted extractant at the interface, it is nearly completely saturated with the extractant molecules and, consequently, the interfacial concentration of the unreacted extractant is nearly constant over the concentration region above $10 \mathrm{mmol} / \mathrm{dm}^{3}$ of 2 -EHO, judging from the experimental result for interfacial tension shown in Fig. 3.

The second-order dependency with respect to the extractant concentration suggests that the ratedetermining step in the present extraction system is neither the first step nor the second step of the 


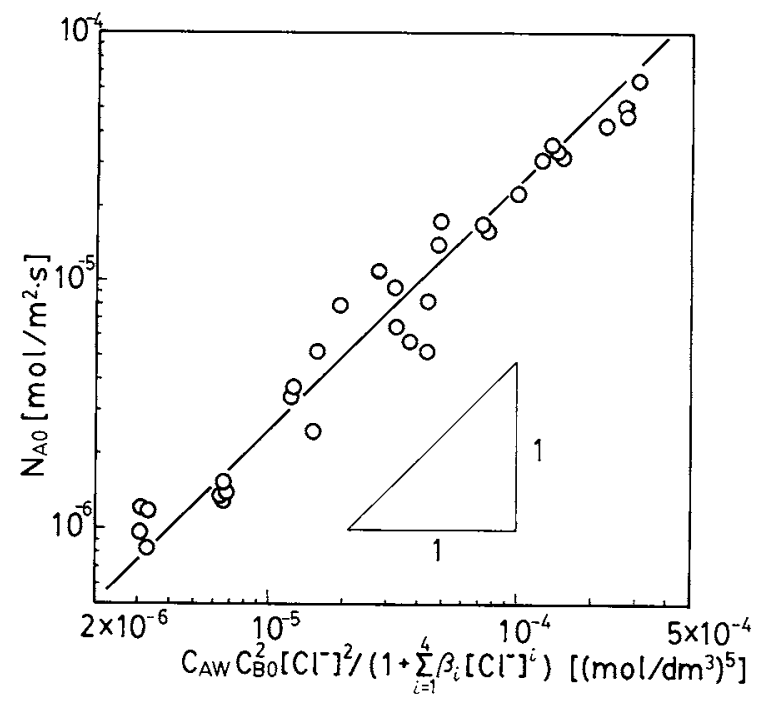

Fig. 6. Plot of kinetic data based on Eq. (17)

consecutive complex formation at the interface described by Eqs. (14) or (15), which would provide 0-th order or first-order dependency with respect to the extractant concentration, respectively, but the desorption of the final complex described by Eq. (16). The initial rate expression for this extraction reaction is ultimately described by Eq. (17) on the basis of the reaction scheme described by Eqs. (13)-(16) along with Eq. (9).

$$
\begin{aligned}
N_{\mathrm{A} 0}= & k_{3} \theta_{\mathrm{CuCl}_{2} \mathrm{~B}_{2}}[\overline{\mathrm{B}}] \\
= & k_{3} K_{1} K_{2} K_{\mathrm{D}} \theta_{\mathrm{B}}\left\{\beta_{2}\left[\mathrm{Cl}^{-}\right]^{2} /\left(1+\sum_{j=1}^{4} \beta_{j}\left[\mathrm{Cl}^{-}\right]^{j}\right)\right\} \\
& \times C_{\mathrm{AW}} C_{\mathrm{BO}}^{2} \\
= & k\left[\mathrm{Cl}^{-}\right]^{2} C_{\mathrm{AW}} C_{\mathrm{BO}}^{2} /\left(1+\sum_{j=1}^{4} \beta_{j}\left[\mathrm{Cl}^{-}\right]^{j}\right)
\end{aligned}
$$

where

$$
k=k_{3} K_{1} K_{2} K_{\mathrm{D}} \beta_{2} \theta_{\mathrm{B}}
$$

and the fractional coverage of the interface by the extractant molecules, $\theta_{\mathrm{B}}$, is nearly constant under the assumption mentioned earlier.

The experimental results shown in Figs. 3, 4 and 5 can be qualitatively interpreted by Eq. (17). All the data shown in these figures were plotted according to Eq. (17) in Fig. 6. Here, the following values were employed as the stability constants for the copper(II)chloro complexes. ${ }^{8)}$

$$
\begin{array}{ll}
\beta_{1}=1.0 & {\left[\left(\mathrm{~mol} / \mathrm{dm}^{3}\right)^{-1}\right]} \\
\beta_{2}=2.0 \times 10^{-1} & {\left[\left(\mathrm{~mol} / \mathrm{dm}^{3}\right)^{-2}\right]} \\
\beta_{3}=6.3 \times 10^{-3} & {\left[\left(\mathrm{~mol} / \mathrm{dm}^{3}\right)^{-3}\right]} \\
\beta_{4}=3.2 \times 10^{-5} & {\left[\left(\mathrm{~mol} / \mathrm{dm}^{3}\right)^{-4}\right]}
\end{array}
$$

The plots in Fig. 6 appear to cluster on a straight line with a slope of 1 as expected from Eq. (17). From the intercept of the straight line with the ordinate in Fig. 6, the apparent reaction rate constant was evaluated as $k=2.5 \times 10^{-16}\left[\left(\mathrm{~m}^{3} / \mathrm{mol}\right)^{4} \mathrm{~m} / \mathrm{s}\right]$. The solid curve in Fig. 5 was calculated from Eq. (17) using $k$ thus evaluated and the stability constants for copper(II)-chloro complexes shown above. The plots are in good agreement with the solid curve.

\section{Conclusion}

The initial forward extraction rate of copper(II) from aqueous sodium chloride solution with 2-EHO in toluene was measured using a stirred transfer cell. It was found to have first-order and second-order dependencies on the concentrations of copper(II) in the aqueous phase and the extractant in the organic phase respectively. On the other hand, a second-order dependence of the extraction rate on the chloride ion concentration was observed in its low-concentration region, while a tendency to approach a constant value was observed in its high-concentration region; this dependence was ascribed to the change of concentration of neutral copper(II)-dichloro complex which participates in the complex formation at the interface with the change of chloride ion concentration. An interfacial reaction model in which the extraction rate is controlled by the desorption of the final complex, $\mathrm{CuCl}_{2} \mathrm{~B}_{2}$, from the interface brought about by substitution with the extractant molecule was proposed to interpret the second-order dependence of the extraction rate on the extractant concentration.

$$
\begin{aligned}
& \text { Nomenclature } \\
& \mathrm{B}=\text { species of } 2-\mathrm{EHO} \\
& C_{\mathrm{A} 0}=\text { concentration of copper(II) extracted into } \\
& \text { organic phase } \quad\left[\mathrm{mol} / \mathrm{dm}^{3}\right] \\
& \begin{aligned}
C_{\mathrm{AW}}= & \begin{array}{r}
\text { total concentration of copper(II) in } \\
\text { aqueous phase }
\end{array} \quad\left[\mathrm{mol} / \mathrm{dm}^{3}\right]
\end{aligned} \\
& \begin{array}{rlr}
C_{\mathrm{BO}}= & \begin{array}{l}
\text { concentration of 2-EHO in } \\
\text { organic phase }
\end{array} & {\left[\mathrm{mol} / \mathrm{dm}^{3}\right]}
\end{array} \\
& \begin{aligned}
C_{\mathrm{BW}}= & \begin{array}{l}
\text { concentration of 2-EHO in } \\
\text { aqueous phase }
\end{array} \\
& {\left[\mathrm{mol} / \mathrm{dm}^{3}\right] }
\end{aligned} \\
& K_{\text {ad }}=\text { interfacial adsorption equilibrium constant } \\
& \text { of } 2 \text {-EHO }\left[\mathrm{m}^{3} / \mathrm{mol}\right] \\
& K_{\mathrm{D}} \quad=\text { partition coefficient of 2-EHO } \quad[-] \\
& K_{1} \quad=\text { equilibrium constant of the elementary step } \\
& \text { described by Eq. (14) } \\
& K_{2}=\text { equilibrium constant of the elementary step } \\
& \text { described by Eq. (15) } \\
& k=\text { apparent reaction rate constant defined by } \\
& \text { Eq. (18) } \quad\left[\left(\mathrm{m}^{3} / \mathrm{mol}\right)^{4} \mathrm{~m} / \mathrm{s}\right] \\
& k_{3}=\text { reaction rate constant of the forward } \\
& \text { reaction of the elementary step described } \\
& \text { by Eq. (16) } \\
& k_{-3}=\text { reaction rate constant of the backward } \\
& \text { reaction of the elementary step described } \\
& \text { by Eq. (16) } \\
& N_{\text {AO }}=\text { initial extraction rate of copper(II) } \quad\left[\mathrm{mol} / \mathrm{m}^{2} \cdot \mathrm{s}\right] \\
& \mathrm{R}=\text { gas constant } \quad[\mathrm{N} \cdot \mathrm{m} /(\mathrm{mol} \cdot \mathrm{K})]
\end{aligned}
$$




\begin{tabular}{|c|c|c|}
\hline$S$ & $=$ contact area of stirred transfer cell & {$\left[\mathrm{m}^{2}\right]$} \\
\hline$S_{\mathrm{B}}$ & $\begin{aligned}= & \text { interfacial area occupied by unit mole } \\
& \text { of } 2-\mathrm{EHO}\end{aligned}$ & {$\left[\mathrm{m}^{2} / \mathrm{mol}\right]$} \\
\hline$T$ & $=$ temperature & {$[\mathrm{K}]$} \\
\hline$t$ & $=$ contact time & {$[\mathrm{s}]$} \\
\hline$V_{\text {org }}$ & $=$ volume of organic phase & {$\left[\mathrm{m}^{3}\right]$} \\
\hline$\beta_{\mathrm{i}}$ & $\begin{aligned}= & \text { stability constant of } i \text {-th copper(II)-chl } \\
& \text { complex }\end{aligned}$ & $\begin{array}{l}\text { loro } \\
\left.\left(\mathrm{mol} / \mathrm{dm}^{3}\right)^{\mathrm{i}}\right]\end{array}$ \\
\hline$\gamma$ & $=$ interfacial tension & {$[\mathrm{N} / \mathrm{m}]$} \\
\hline$\gamma_{0}$ & $\begin{array}{l}=\text { interfacial tension between pure diluent } \\
\text { and aqueous solution }\end{array}$ & {$[\mathrm{N} / \mathrm{m}]$} \\
\hline$\theta_{\mathrm{i}}$ & $\begin{aligned}= & \text { fractional coverage of interface with } \\
& i \text {-th adsorptive species }\end{aligned}$ & {$[-]$} \\
\hline ] & $=$ concentration & {$\left[\mathrm{mol} / \mathrm{dm}^{3}\right]$} \\
\hline & $=$ organic phase & \\
\hline
\end{tabular}

\section{Literature Cited}

1) Baba, Y., T. Eguchi and K. Inoue: Bull. Chem. Soc. Jpn., 59, 1321 (1986).

2) Baba, Y., M. Ohshima and K. Inoue: Bull. Chem. Soc. Japan, 59, 3829 (1986).

3) Burkin, A. R. and J. S. Preston: J. Inorg. Nucl. Chem., 37
2187 (1975).

4) Danesi, P. R. and R. Chiarizia: J. Inorg. Nucl. Chem., 40, 1811 (1978).

5) Danesi, P. R., R. Chiarizia and M. Muhammed: J. Inorg. Nucl. Chem., 40, 1581 (1978).

6) Danesi, P. R., R. Chiarizia and A. Saltelli: J. Inorg. Nucl. Chem., 38, 1687 (1976).

7) Eigen, M. and K. Tamm: Z. Elektrochem., 66, 107 (1962)

8) Freiser, H. and Q. Fernando: "Ionic Equilibria in Analytical Chemistry (in Japanese translation)," translated by T. Fujinaga and E. Sekido, p. 254, Kagaku Dojin, Kyoto (1976).

9) Inoue, K., Y. Baba, T. Oka and M. Takagi: Japanese Patent (Kokai), 61-238,927 (1986).

10) Inoue, K., Y. Baba, T. Oka, M. Takagi and K. Dohtsu: Solvent Extr. Ion Exch., 4, 237 (1986).

11) Inoue, K., Y. Kawano, F. Nakashio and W. Sakai: Kagaku Kōgaku, 38, 41 (1974).

12) Inoue, K. and F. Nakashio: Kagaku Kōgaku, 46, 164 (1982).

13) Uhlig, E. and J. Becher: Z. Anorg. Allg. Chem., 518, 2187 (1975).

14) Yoshizuka, K., K. Kondo and F. Nakashio: J. Chem. Eng. Japan, 18, 163 (1985).

\title{
EFFECT OF PERMEATION THROUGH STATOR ON THE HYDRODYNAMICS OF A ROTATING DISK DYNAMIC FILTER
}

\author{
WEI-MING LU AND CHING-JUNG CHUANG \\ Department of Chemical Engineering, National Taiwan University, \\ Taipei, Taiwan, R.O.C.
}

Key Words : Fluid Mechanics, Rotating Disk, Dynamic Filter

Fluid flow between a rotating disk and a stationary septum such as that in a rotating disk dynamic filter was studied theoretically and experimentally. The Navier-Stokes equations were solved in the laminar flow region of $R e<10^{4}$ under reasonable fluid permeation rates through the stationary disk. The velocity profiles obtained by numerical calculation agree very well with the results determined by LDA measurement. Distributions of shear stress acting on the rotating disk and stationary septum are also presented in this study.

\section{Introduction}

The problem of fluid flow between a stationary and a rotating disk confined in a housing is of considerable interest to many researchers and engineers in various fields of fluid mechanics. The fluid flow in disk-type dynamic filters is a problem generalized in the same category except that there exists vertical permeation through the stationary filter septum.

Received August 29, 1987. Correspondence concerning this article should be ad. dressed to W. M. Lu.
Shear stress induced by the rotating disk prevents further formation of filter cake, and thus results in a higher average filtration rate. The characteristics of filtration and washing operations as well as power consumption of such filters have been studied thoroughly by many investigators. ${ }^{1,14,15,17)}$ However, only a few have paid attention to the shearing action of fluid flow in the filters. ${ }^{79}$ To understand the performance of a dynamic filter, it is essential to know the hydrodynamics in the filter chamber.

Fluid flow between a rotating disk and a stationary 